\title{
Labor dystocia and risk of histological chorioamnionitis and funisitis: a study from a single tertiary referral center
}

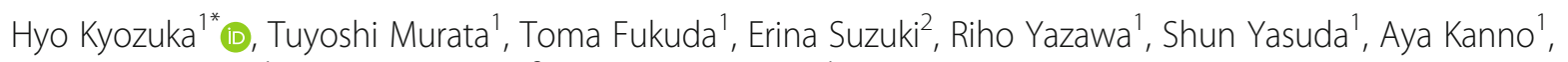
Akiko Yamaguchi ${ }^{1}$, Yuko Hashimoto ${ }^{2}$ and Keiya Fujimori ${ }^{1}$

\begin{abstract}
Background: Intrauterine inflammation affects short- and long-term neonatal outcomes. Histological chorioamnionitis and funisitis are acute inflammatory responses in the fetal membranes and umbilical cord, respectively. Although labor dystocia includes a potential risk of intrauterine inflammation, the risk of histological chorioamnionitis and funisitis of labor dystocia has not been evaluated yet. This study aimed to examine the association between labor dystocia and risk of histological chorioamnionitis and funisitis.

Methods: In this retrospective cohort study, the cases who underwent histopathological examinations of the placenta and umbilical cord at Fukushima Medical University Hospital, Japan, between 2015 and 2020, were included. From the dataset, the pathological findings of the patients with labor dystocia and spontaneous preterm birth were reviewed. Based on the location of leukocytes, the inflammation in the placenta (histological chorioamnionitis) and umbilical cord (funisitis) was staged as 0-3. Multiple logistic regression analysis was performed to evaluate the risk of histological chorioamnionitis, histological chorioamnionitis stage $\geq 2$, funisitis, and funisitis stage $\geq 2$.

Result: Of 317 women who met the study criteria, 83 and 144 women had labor dystocia and spontaneous preterm birth, respectively, and 90 women were included as controls. Labor dystocia was a risk factor for histological chorioamnionitis (adjusted odds ratio, 6.3; 95\% confidential interval, 1.9-20.5), histological chorioamnionitis stage $\geq 2$ (adjusted odds ratio, 6.0; 95\% confidence interval, 1.7-21.8), funisitis (adjusted odds ratio, 15.4; 95\% confidence interval, 2.3-101.3), and funisitis stage $\geq 2$ (adjusted odds ratio, 18.5; 95\% confidence interval, 2.5-134.0). Spontaneous preterm birth was also a risk factor for histological chorioamnionitis (adjusted odds ratio, 3.7; 95\% confidence interval, 1.7-7.8), histological chorioamnionitis stage $\geq 2$ (adjusted odds ratio, 3.0; 95\% confidence interval, 1.2-7.9), and funisitis (adjusted odds ratio, 6.6; 95\% confidence interval, 1.4-30.6). However, the adjusted odds ratio was smaller in spontaneous preterm births than in labor dystocia.
\end{abstract}

Conclusion: Labor dystocia is a risk factor for severe histological chorioamnionitis and funisitis. Further studies are required to evaluate the effects of histological chorioamnionitis and funisitis on long-term neonatal outcomes.

Keywords: Labor dystocia, Intrauterine inflammation, Histological chorioamnionitis, Funisitis, Staging

\footnotetext{
* Correspondence: kyozuka@fmu.ac.jp

'Department of Obstetrics and Gynecology, Fukushima Medical University

School of Medicine, 1 Hikarigaoka, Fukushima 960-1295, Japan

Full list of author information is available at the end of the article
}

(c) The Author(s). 2021 Open Access This article is licensed under a Creative Commons Attribution 4.0 International License, which permits use, sharing, adaptation, distribution and reproduction in any medium or format, as long as you give appropriate credit to the original author(s) and the source, provide a link to the Creative Commons licence, and indicate if changes were made. The images or other third party material in this article are included in the article's Creative Commons licence, unless indicated otherwise in a credit line to the material. If material is not included in the article's Creative Commons licence and your intended use is not permitted by statutory regulation or exceeds the permitted use, you will need to obtain permission directly from the copyright holder. To view a copy of this licence, visit http://creativecommons.org/licenses/by/4.0/ The Creative Commons Public Domain Dedication waiver (http://creativecommons.org/publicdomain/zero/1.0/) applies to the data made available in this article, unless otherwise stated in a credit line to the data. 


\section{Background}

Chorioamnionitis (CAM) is strongly related to preterm birth (PTB), which can lead to significant neonatal morbidity and mortality, including periventricular leukomalacia, bronchopulmonary dysplasia, pneumonia, and cerebral palsy [1-3]. Histological CAM (hCAM) is the maternal response to inflammatory stimuli in the amniotic cavity [4,5] and is diagnosed pathologically after delivery. hCAM is not always associated with fetal infection or fetal inflammatory response syndrome. Funisitis, an inflammatory process involving the umbilical cord, is an accepted hallmark of fetal inflammatory response syndrome. Although both hCAM and funisitis are acute inflammatory lesions with important short- and longterm clinical significance [6], funisitis is associated with higher rates of neonatal morbidity and multi-organ fetal involvement than CAM $[7,8]$.

Recently, the descriptive term "intrauterine inflammation or infection or both" abbreviated as "Triple I" has been proposed by the National Institute of Child Health and Human Development expert panel to replace the term CAM [9]. This new term indicates that hCAM and funisitis do not always occur along with PTB and CAM is sometimes diagnosed based on the presence of inflammation of the placenta or umbilical cord without clinical symptom of infection.

Our previous study that examined the association between the fetal heart rate and risk of intrauterine inflammation in cases of PTB showed that vaginal delivery increased the risk of hCAM [10]. Therefore, uterine contractions (UC) might be a risk factor for intrauterine inflammation. Labor dystocia (LD) is the arrest of labor and one of the commonest obstetric complications in primiparous women that justifies medical intervention during labor [11, 12]. LD increases the risk of operative vaginal delivery, cesarean section (CS), and postpartum hemorrhage $[13,14]$. While UCs could increase the risk of intrauterine inflammation, the effects of LD on hCAM and funisitis are not well known. Hence, the present study aimed to examine whether LD is a risk factor for hCAM and funisitis. Specifically, we have focused on the following two questions in this study: (i) does the risk of hCAM and funisitis differ between LD and spontaneous PTB (SPTB) cases and (ii) does LD affect the severity of inflammation in the placenta or the umbilical cord?

\section{Methods}

\section{Study patients}

In this retrospective cohort study, data from women whose placenta and umbilical cord were histopathologically examined at Fukushima Medical University Hospital, Fukushima, Japan, between July 1, 2015, and June 30, 2020, were assessed. Information on maternal and obstetric outcomes was retrieved from the medical records. In our institution, histopathological examinations of the placenta and umbilical cord are usually conducted in the following conditions: 1) SPTB before 37 weeks gestation; 2) hypertensive disorders of pregnancy; 3) clinical CAM in delivery after 37 weeks gestation; 4) placental abruption; 5) placenta accreta spectrum; 6) abnormal fetal heart rate pattern; 7) fetal abnormality, such as fetal growth restriction and fetal anomaly, which includes medically induced PTB; 8) intrauterine fetal death; and 9) LD. SPTB is defined as delivery before 37 weeks gestation due to $\mathrm{UC}$ or premature rupture of membranes. Hypertensive disorders of pregnancy is defined as new onset of hypertension (blood pressure $\geq 140 / 90 \mathrm{mmHg}$ ) after conception. Clinical CAM is diagnosed according to the Lencki criteria (maternal fever with positive findings on blood investigations, presence of discharge, abdominal pain, or maternal tachycardia) [15]. Abnormal fetal heart rate pattern is defined as Category III, which is proposed by the National Institute of Child Health and Human Development workshop [16]. LD is defined as follows: a case with cephalic presentation without a history of CS and (1) operative vaginal delivery with several trials of maternal effort due to arrest of the active phase for at least $4 \mathrm{~h}$ when the dilation of the cervix was $10 \mathrm{~cm}$ with or without an augmentation agent or (2) no progress with cervical dilation despite clinically adequate effective labor irrespective of augmentation, such as the use of oxytocin or amniotomy. Women with multiple gestations, delivery before 22 weeks gestation, clinical CAM after 37 weeks gestation, hypertensive disorders of pregnancy, placental abruption, placenta accreta, abnormal fetal heart rate pattern, and intrauterine fetal death were excluded from the present analysis.

Information on maternal and obstetric outcomes was retrieved from the medical records. Maternal information included maternal age (categorized as $<30,30-39$, $35-39$, and $\geq 40$ years) and gestational age at the time of examination. Gestational age was determined at an early stage of pregnancy based on the last menstrual period and/or ultrasound examination findings. Duration of labor was defined as the presence of true labor pain until the end of their delivery.

\section{Histological examination of the placenta and umbilical cord}

In our institution, histological examinations of the placenta and umbilical cord were routinely conducted for the cases mentioned above. The following sites were sampled: the chorion-amnion, chorionic plate, and umbilical cord. In our institution, we usually sample from about 10 points; 2 cross sections of the umbilical cord, one from near the cord insertion and another 
approximately $5 \mathrm{~cm}$ from the umbilical cord Insertion to placenta. A one roll of the extraplacental membranes, 5 to 7 other placental sample each containing a full thickness section near by placenta to cord insertion, and other significant lesions such as hemorrhage and ischemia. These samples were fixed in $10 \%$ neutral buffered formalin and embedded in paraffin. Sections of tissue blocks were stained with hematoxylin and eosin. Based on the location of leukocytes, inflammation in the placenta and umbilical cord was staged according to Amsterdam Placental Workshop Group Consensus Statement (Table 1) [17].

\section{Statistical analyses}

In the present study, cases of fetal abnormality were used as controls. Since SPTB is known to be associated with intrauterine inflammation, we assessed the risk of intrauterine inflammation in cases with LD in comparison to the risk of not only the controls but also cases with SPTB. Due to the present study's retrospective design, as many participants as possible who were examined during this study period were included.

Maternal information and obstetric outcomes of the LD, SPTB, and control groups were summarized. The labor duration was compared among cases classified based on the presence of intrauterine inflammation (hCAM, hCAM stage $\geq 2$, funisitis, and funisitis stage $\geq 2$ ). Finally, we determined the risk hCAM and funisits due to LD and SPTB by performing a logistic regression analysis, accounting for maternal age $(<30$ years as reference), method of delivery (vaginal delivery or CS), gestational age (continuous variable), duration of labor (continuous variable), and parity (multipara or primiparous). SPSS v26 (IBM Corp., Armonk, NY, USA) was used for the statistical analyses. Mann-Whitney U tests and one-way analysis of variance were used to compare

Table 1 Inflammatory staging of the umbilical cord and placenta [17]

\begin{tabular}{ll}
\hline Score of the umbilical cord \\
\hline Stage & Interpretation \\
\hline 1 & $\begin{array}{l}\text { Chorionic vasculitis or umbilical phlebitis } \\
2\end{array}$ \\
3 & $\begin{array}{l}\text { Involvement of the umbilical vein and one or more umbilical } \\
\text { Necrotizing funisitis }\end{array}$ \\
Score of the placenta \\
Stage & $\begin{array}{l}\text { Interpretation } \\
1\end{array}$ \\
2 & $\begin{array}{l}\text { Acute subchorionitis or chorionitis } \\
\text { into fibrous chorion and/or amnion }\end{array}$ \\
3 & $\begin{array}{l}\text { Necrotizing chorioamnionitis: karyorrhexis of polymorphonuclear } \\
\text { leukocytes, amniocyte necrosis, and/or amnion basement } \\
\text { membrane hypereosinophilia }\end{array}$ \\
\hline
\end{tabular}

the continuous variables. Chi-squared tests were used to compare the categorical variables. To calculate the adjusted odds ratios (aORs) and 95\% confidence intervals (CIs), a multiple logistic regression model was used. The level of statistical significance was set at $P<0.05$.

\section{Results}

Fig. 1 shows the inclusion of the study participants. During the study period, there were 1967 deliveries at Fukushima Medical University Hospital. Among them, histopathological examination of the placenta was performed in 778 cases; of these, 212 and 44 cases were excluded because of multiple pregnancies and delivery before 22 weeks, respectively. Furthermore, 43, 62, 37, 24, 30, and 9 cases were excluded because of clinical CAM, hypertensive disorders of pregnancy, placental abruption, placenta accreta spectrum, non-reassuring fetal status, and intrauterine fetal death, respectively. As a result, 317 cases were eligible for the final analysis. They were categorized as "LD" $(n=83)$, "SPTB" $(n=$ $144)$, and controls $(n=90)$, which included 53 and 37 cases of fetal anomaly and growth restriction and delivery without UC, respectively.

Table 2 shows the basic characteristics of the women in the three groups. Both mean maternal age and maternal age category were significantly different among the groups. The LD group tended to have more patients aged 30-39 years. The rates of primiparous and CS delivery in the LD group were 91.6 and $83.1 \%$, respectively, and were significantly higher than those of the SPTB and control groups $(P<0.01$ and $P<0.05$, respectively). The mean (standard deviation) gestational age at delivery in patients in the LD, SPTB, and control groups was 39.6 (1.2), 30.7 (5.1), and 35.9 (3.4) weeks, respectively, which were significantly different $(P<0.001)$. Although the incidence of umbilical cord artery (UmA) $\mathrm{pH}<7.20$ was not significantly different among the three groups $(P=0.310)$, the mean $\mathrm{pCO}_{2}, \mathrm{pO}_{2}$, and base excess $(\mathrm{BE})$ in the UmA were significantly different $(P<0.05, P<$ 0.01 , and $P<0.01$, respectively).

Table 3 shows the incidence of hCAM and funisitis and their staging in the LD, SPTB, and control groups. The incidence of hCAM and funisitis in the control group was 14.4 and $3.4 \%$, respectively. The incidence of hCAM and funisitis in the LD group was 63.9 and $39.2 \%$, respectively, which were significantly higher than those of the other two groups. The incidence of hCAM and funisitis $\geq$ stage 2 were also the highest in the LD group (54.2 and $32.1 \%$, respectively).

Table 4 shows the comparisons of the results of the UmA gas analysis at delivery between the LD and control groups. Both the mean UmA pH and incidence of UmA $\mathrm{pH}<7.20$ were not significantly different between the two groups $(P=0.465$ and $P=0.213$, respectively). 


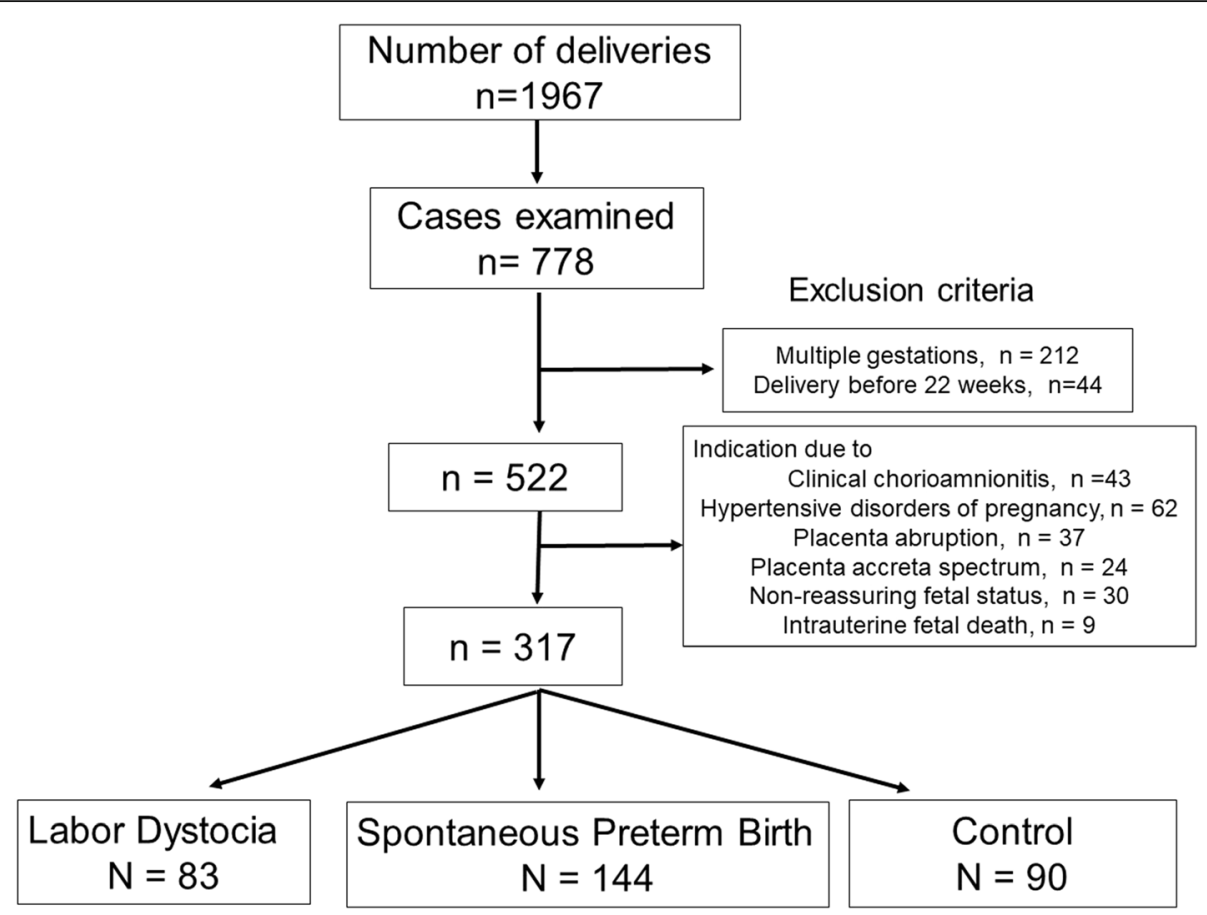

Fig. 1 A flow chart depicting the study design

The mean $\mathrm{UmA} \mathrm{CO}_{2}$ was significantly higher in the control group (44.7 vs. $48.6 \mathrm{mmHg}$, respectively, $P<0.01$ ), whereas the mean BE was significantly higher in the LD group ( -5.1 vs. -4.0 , respectively, $P<0.01$ ).

Table 5 shows the comparisons of labor duration between LD cases classified based on the presence or absence of histological inflammation. Mann-Whitney U test showed that there was no significant difference in the labor duration between the cases with and without inflammation, such as hCAM, hCAM stage $\geq 2$, funisitis, and funisitis stage $\geq 2(P=0.837, P=0.790, P=0.476$, and $P=0.211$, respectively).

Table 6 shows the association between LD, SPTB, and intrauterine inflammation. LD was a risk factor for hCAM (aOR: 6.3, 95\% CI: 1.9-20.5), hCAM stage $\geq 2$ (aOR: 6.0, 95\% CI: 1.7-21.8), funisitis (aOR: 15.4, 95\%

Table 2 Basic maternal characteristics of the LD, SPTB, and control groups

\begin{tabular}{|c|c|c|c|c|}
\hline \multirow[b]{3}{*}{ Variable } & \multicolumn{3}{|c|}{ Participants } & \multirow[b]{3}{*}{$P$-value } \\
\hline & $\overline{\mathrm{LD}}$ & SPTB & Control & \\
\hline & $n=83$ & $n=144$ & $n=90$ & \\
\hline Maternal age, years & $34.2(5.8)$ & $31.9(6.2)$ & $31.4(6.1)$ & $<0.01^{\mathrm{a}}$ \\
\hline \multicolumn{5}{|l|}{ Maternal age category, \% } \\
\hline$<30$ years & 24.1 & 34.7 & 38.9 & \multirow[t]{3}{*}{$<0.05^{\mathrm{b}}$} \\
\hline 30-39 years & 54.2 & 56.9 & 52.2 & \\
\hline$>40$ years & 21.7 & 8.3 & 8.9 & \\
\hline Maternal height, cm & $157(6.0)$ & $158(5.9)$ & $158(5.8)$ & $0.343^{\mathrm{a}}$ \\
\hline Primiparous, \% & 91.6 & 47.2 & 58.9 & $<0.01^{\mathrm{b}}$ \\
\hline Cesarean section, \% & 83.1 & 64.6 & 66.7 & $<0.05^{\mathrm{b}}$ \\
\hline Gestational age at delivery, weeks & $39.6(1.2)$ & $30.7(5.1)$ & $35.9(3.4)$ & $<0.01^{\mathrm{a}}$ \\
\hline Birth weight at delivery, $\mathrm{g}$ & $3143(398)$ & $1637(836)$ & $2160(770)$ & $<0.01^{\mathrm{a}}$ \\
\hline
\end{tabular}

Results are expressed as mean (standard deviation) unless specified otherwise

$L D$ labor dystocia, SPTB spontaneous preterm birth

${ }^{\text {a }}$-value: one-way analysis of variance

${ }^{\mathrm{b}} P$-value: chi-squared test 
Table 3 The stage of CAM and funisitis in LD, SPTB, and control groups

\begin{tabular}{lllll}
\hline Variable & \multicolumn{2}{l}{ Participants } & P-value \\
\cline { 2 - 4 } & LD & SPTB & Control & \\
& $\boldsymbol{n}=\mathbf{8 3}$ & $\boldsymbol{n}=\mathbf{1 4 4}$ & $\boldsymbol{n}=\mathbf{9 0}$ & \\
\hline CAM, \% & 63.9 & 52.1 & 14.4 & $<0.01$ \\
CAM stage, \% & & & & \\
Not presence & 36.1 & 47.9 & 85.6 & $<0.01$ \\
1 & 9.6 & 14.6 & 6.7 & \\
2 & 24.1 & 13.2 & 1.1 & \\
3 & 30.1 & 24.3 & 6.7 & \\
CAM stage $\geq 2, \%$ & 54.2 & 37.5 & 7.8 & $<0.01$ \\
Funisitis, \% & 39.2 & 24.8 & 3.4 & $<0.01$ \\
Funisitis stage, \% & & & & \\
Not presence & 61.7 & 75.2 & 97.7 & $<0.01$ \\
1 & 4.9 & 3.5 & 0.0 & \\
2 & 32.1 & 18.4 & 2.3 & \\
3 & 1.2 & 2.8 & 0.0 & $<0.01$ \\
\hline Funisitis stage $\geq 2, \%$ & 32.1 & 21.3 & 2.3 & \\
\hline $\begin{array}{l}\text { CAM chorioamnionitis, LD labor dystocia, SPTB spontaneous preterm birth } \\
\text { a P-value: chi-squared test }\end{array}$ & & & &
\end{tabular}

CI: 2.3-101.3), and funisitis stage $\geq 2$ (aOR: 18.5, 95\% CI: 2.5-134.0). SPTB was also a risk factor for hCAM (aOR: 3.7, 95\% CI: 1.7-7.8), hCAM stage $\geq 2$ (aOR: $2.8,95 \%$ CI: 1.2-7.9), and funisitis (aOR: 6.6, 95\% CI: 1.4-30.6).

\section{Discussion}

This is the first study to examine the correlation between LD and risk of intrauterine inflammation in both hCAM and funisitis cases. Since we did not have histopathological information on cases with so-called normal progress of labor, we defined those with fetal abnormalities as controls and also examined the association between SPTB and intrauterine inflammation to compare the degree of risk of intrauterine inflammation between the LD and SPTB cases. We found a significant

Table 4 Comparison of UmA gas analysis at delivery between LD and control groups

\begin{tabular}{llll}
\hline Variable & \multicolumn{2}{l}{ Participants } & P-value \\
\cline { 2 - 3 } & LD & Control & \\
& $\boldsymbol{n}=\mathbf{8 3}$ & $\boldsymbol{n = 8 7}$ & \\
\hline $\mathrm{pH}$ & $7.30(0.06)$ & $7.29(0.07)$ & $0.465^{\mathrm{a}}$ \\
$\mathrm{pH}<7.20, \%$ & 3.6 & 9.2 & $0.213^{\mathrm{b}}$ \\
$\mathrm{pCO}_{2}, \mathrm{mmHg}$ & $44.7(8.0)$ & $48.6(10.0)$ & $<0.01^{\mathrm{a}}$ \\
$\mathrm{pO}_{2}, \mathrm{mmHg}$ & $17.7(6.0)$ & $17.4(6.6)$ & $0.781^{\mathrm{a}}$ \\
$\mathrm{BE}_{1} \mathrm{mmol} / \mathrm{L}$ & $-5.1(2.8)$ & $-4.0(3.2)$ & $<0.05^{\mathrm{a}}$ \\
\hline
\end{tabular}

Results are specified as mean (standard deviation) unless specified otherwise LD: labor dystocia, BE: base excess, UmA: Umbilical artery

${ }^{a} P$-value: t-test

${ }^{\mathrm{b}} P$-value: chi-squared test
Table 5 Comparison of labor duration based on the presence or absence of intrauterine inflammation in LD

\begin{tabular}{llll}
\hline & Positive & Negative & $P_{\text {-value }}$ \\
\hline CAM, n & 51 & 30 & \\
hours, median (IQR) & $9(6-14)$ & $8(7-14)$ & 0.837 \\
CAM stage $22, n$ & 44 & 37 & \\
hours, median (IQR) & $9(6-14)$ & $8(7-15)$ & 0.79 \\
Funisitis, n & 33 & 48 & \\
hours, median (IQR) & $9(6-14)$ & $9(7-14)$ & 0.476 \\
Funisitis stage $\geq 2, n$ & 29 & 52 & \\
hours, median (IQR) & $9(6-14)$ & $9(7-17)$ & 0.211 \\
\hline LD labor dystocia, CAM chorioamnionitis, IQR interquartile range & \\
aP-value: Mann-Whitney U test & &
\end{tabular}

difference in maternal age, parity, mode of delivery, and gestational age at delivery among the three groups. After accounting for confounding factors, we found that SPTB was associated with hCAM, hCAM stage $\geq 2$, and funisitis. We also found the association of LD with hCAM, hCAM stage $\geq 2$, funisitis, and funisitis stage $\geq 2$. The magnitude of aOR in LD and SPTB for each intrauterine inflammation event (6.3 and 3.7 for hCAM, 6.0 and 3.0 for hCAM stage $\geq 2$, and 15.4 and 6.6 for funisitis, respectively) indicated that the risk of inflammation was higher in LD than in SPTB.

Our finding that LD, which is characterized by ineffective UC, is associated with hCAM and funisitis is in accordance with that of a previous study. Lee et al. reported that the frequencies of hCAM and funisitis in spontaneous term deliveries were $23.6 \%$ (310/1316) and $6.7 \%(88 / 1316)$, respectively. They also reported the association of longer labor duration, primiparous, rupture of membranes, and higher gestational age with both hCAM and funisitis in term spontaneous deliveries [18]. However, reports on the association between UC and funisitis are conflicting. Seong et al. reported that labor was associated with an increased risk of microbial invasion of the amniotic cavity and hCAM in term pregnancies. They also reported that the more advanced the cervical dilatation, the greater is the risk of microbial invasion of the amniotic cavity and hCAM. However, the risk of funisitis was not reported to increase with the presence of labor or as a function of cervical dilatation [19].

Compared to the previous study, we used the staging system based on Amsterdam Placental Workshop Group Consensus Statement [17]. Consequently, we found that LD was more strongly associated with hCAM and funisitis compared with SPTB by mean of magnitude of aOR. However, we did not assessed the severity of inflammation which is defined using a grading system in the Amsterdam Placental Workshop Group Consensus Statement [17], further studies are required to validate if 
Table 6 The risk of hCAM and funistis in LD and SPTB

\begin{tabular}{lllll}
\hline & hCAM & hCAM $\geq \mathbf{2}$ & Funisitis & Funisitis $\geq \mathbf{2}$ \\
\hline LD $(+)$ OR $(95 \%$ Cl) & $10.5(5.0-21.9)$ & $14.1(5.8-34.0)$ & $26.3(6.1-114.8)$ & $20.1(4.6-88.1)$ \\
LD $(+)$ aOR $(95 \%$ Cl) & $6.3(1.9-20.5)$ & $6.0(1.7-21.8)$ & $15.4(2.3-101.3)$ & $18.5(2.5-134.0)$ \\
SPTB $(+)$ OR $(95 \%$ Cl) & $6.0(3.1-11.5)$ & $6.3(2.8-13.9)$ & $14.0(3.3-60.0)$ & $11.5(2.7-49.4)$ \\
SPTB $(+)$ aOR $(95 \%$ Cl) & $3.7(1.7-7.8)$ & $3.0(1.2-7.9)$ & $6.6(1.4-30.6)$ & $3.6(0.7-17.6)$ \\
\hline
\end{tabular}

hCAM histological chorioamnionitis, $L D$ labor dystocia, SPTB spontaneous preterm birth, OR odds ratio, aOR adjusted odds ratio, $C l$ confidential interval aOR was calculated accounting for maternal age ( $<30$ years as reference), parity (0: primiparous, 1 : multipara), mode of delivery (0: cesarean delivery, 1 : vaginal delivery), gestational age (continuous variable), and duration of labor (continuous variable)

pathological staging system of inflammation based on the Amsterdam Placental Workshop Group Consensus Statement [17] in LD is a reliable method to provide clinical meaning to neonatal outcomes.

Our findings revealed higher $\mathrm{pCO}_{2}$ in controls that could lead to respiratory acidosis and lower $\mathrm{BE}$ in $\mathrm{LD}$ cases that could lead to metabolic acidosis. These results are biologically plausible because our previous animal study with an intrauterine inflammation pregnant sheep model proved that the histological inflammation directly caused metabolic acidosis, and not respiratory acidosis [20].

Previously, we have reported that labor UC and immature gestational age at delivery were related to hCAM in SPTB cases [10]. The reason why UC leads to intrauterine inflammation is still unclear. One reason may be that the vaginal fluid is drawn into the uterine cavity by UCs, thus resulting in intrauterine inflammation. A previous study (involving sonohysterography with contrast media) reported that UC acted as a peristaltic pump by which the vaginal fluid could ascend into the uterine cavity [21]. Therefore, exposure to non-effective UC could be a potential risk factor for intrauterine inflammation. Kim et al. reported that intra-amniotic inflammation was present in $12 \%$ of patients with regular UC without cervical changes, while culture-proven intraamniotic infection was present in $3 \%$ of the patients [22]. Therefore, intrauterine inflammation due to UC should be interpreted cautiously because inflammation could occur without an intrauterine infection, which is typical of intrauterine inflammation [23].

Recently, the mean maternal age and ratio of nulliparous cases are increasing in Japan [24]. These cases are more likely to present with $\operatorname{LD}[14,25,26]$ and underline the necessity of obstetrical management not only because LD increases maternal morbidity, such as postpartum transfusion, third- or fourth-degree perineal lacerations, and emergency cesarean or operative vaginal delivery [27], but also because intrauterine inflammation could affect the offspring's health in the long term. Therefore, obstetricians need to pay increased attention to cases with a potential risk for LD to prevent intrauterine inflammation.

The main strength of the present study is that the data were derived from a single tertiary care fetal medicine unit where all women who delivered were managed using approximately the same protocol. The other strength is the information regarding the severity of inflammation using the Blanc/Nakayama classification. Evidence suggests that an enhanced fetal cytokine release as part of the fetal inflammatory response syndrome may directly injure the developing brain [28]; therefore, we will examine the relationship between the degree of inflammation due to LD and long-term neonatal outcomes in future studies.

The present study has some limitations. First, we do not have information on the maternal or neonatal blood tests performed at the time of delivery, because we do not routinely perform such tests except in cases of suspected clinical CAM. Therefore, we categorized the cases with maternal fever as clinical CAM and excluded them from the present analysis. Second, we chose cases with fetal abnormality as the controls because we do not routinely perform placental histopathological examination in healthy cases. Therefore, they may not represent the truly healthy cases. For example, the mean gestational age ( 35.9 weeks) and the ratio of CS (66.7\%) in the control group were quite different compared with the Japanese epidemiological data during the same period at the same place [29]. To minimize this limitation, we also calculated the risk of intrauterine inflammation in the SPTB group and compared the aORs between the cases with LD and those with SPTB. Third, although we accounted for the duration of labor in the logistic model, we did not classify LD into dystocia during the latent and active phases. Fourth, we did not conduct a power analysis for the appropriate number of patients required in this study, and it is unclear whether the sample size was sufficient to achieve statistical significance. Finally, although we excluded cases with maternal fever, we did not have information on the culture tests of the vaginal or amniotic fluids, which could determine whether the pathological inflammation was due to either infection or non-specific inflammation [30].

\section{Conclusion}

Compared with SPTB, LD is a potential risk factor for intrauterine inflammation, especially in severe cases; therefore, obstetricians must pay attention to pregnant women at a potential high risk for LD. Further studies that examine the long-term neonatal outcomes in patients with intrauterine inflammation due to LD are required. 


\section{Abbreviations}

CAM : Chorioamnionitis; PTB : Preterm birth; hCAM : Histological CAM; LD : Labor dystocia; aOR : Adjusted odds ratio; Cl : Confidential interval; SPTB

: Spontaneous preterm birth; CS : Cesarean section; UC: Uterine contraction

\section{Acknowledgments}

None.

\section{Authors' contributions}

All authors approved the final manuscript. H.K. initiated the concept and designed the study to which T.M., T.F., A.Y., S.Y., Y.H., and K. F gave advice. R.Y., E.S., A.K., and Y.H. collected the data. H.K. analyzed the data and wrote the manuscript. All coauthors reviewed the manuscript and gave critical advice.

\section{Funding}

This research did not receive any specific grant from funding agencies in the public, commercial, or not-for-profit sector.

\section{Availability of data and materials}

The data that support the findings of this study are available from the corresponding author upon reasonable request.

\section{Declarations}

\section{Ethics approval and consent to participate}

The study was approved by the Institutional Review Board of Fukushima Medical University (No. 2020190) and the requirement for obtaining patients' informed consent was waived because of retrospective study. All procedures in this study were performed in accordance with the ethical standards of the institutional and/or national research committee and the 1964 Helsinki declaration and its later amendments or comparable ethical standards.

\section{Consent for publication}

Not applicable.

\section{Competing interests}

The authors declare that they have no competing interests.

\section{Author details}

${ }^{1}$ Department of Obstetrics and Gynecology, Fukushima Medical University School of Medicine, 1 Hikarigaoka, Fukushima 960-1295, Japan. ²Department of Diagnostic Pathology, Fukushima Medical University School of Medicine, 1 Hikarigaoka, Fukushima 960-1295, Japan.

\section{Received: 3 December 2020 Accepted: 12 March 2021}

\section{Published online: 30 March 2021}

\section{References}

1. Willoughby RE Jr, Nelson KB. Chorioamnionitis and brain injury. Clin Perinatol. 2002:29(4):603-21. https://doi.org/10.1016/S0095-5108(02)00058-1.

2. Wu YW, Colford JM Jr. Chorioamnionitis as a risk factor for cerebral palsy: a meta-analysis. JAMA. 2000;284(11):1417-24. https://doi.org/10.1001/jama.2 84.11.1417.

3. Jobe $\mathrm{AH}$. Antenatal factors and the development of bronchopulmonary dysplasia. Semin Neonatol. 2003;8(1):9-17. https://doi.org/10.1016/S1084-2 756(02)00188-4

4. Yasuda S, Tanaka M, Kyozuka H, Suzuki S, Yamaguchi A, Nomura Y, et al. Association of amniotic fluid sludge with preterm labor and histologic chorioamnionitis in pregnant Japanese women with intact membranes: a retrospective study. J Obstet Gynaecol Res. 2020;46(1):87-92. https://doi. org/10.1111/jog.14141.

5. Romero R, Chaemsaithong P, Docheva N, Korzeniewski SJ, Kusanovic JP, Yoon BH, et al. Clinical chorioamnionitis at term Vl: acute chorioamnionitis and funisitis according to the presence or absence of microorganisms and inflammation in the amniotic cavity. J Perinat Med. 2015;44:35-51.

6. Kim CJ, Romero R, Chaemsaithong P, Chaiyasit N, Yoon BH, Kim YM. Acute chorioamnionitis and funisitis: definition, pathologic features, and clinical significance. Am J Obstet Gynecol. 2015;213(4):S29-52. https://doi.org/10.1 016/j.ajog.2015.08.040.
7. von Ehrenstein OS, Neta GI, Andrews W, Goldenberg R, Goepfert A, Zhang J. Child intellectual development in relation to cytokine levels in umbilical cord blood. Am J Epidemiol. 2012;175(11):1191-9. https://doi.org/10.1093/a je/kwr393.

8. Jessop FA, Lees CC, Pathak S, Hook CE, Sebire NJ. Funisitis is associated with adverse neonatal outcome in low-risk unselected deliveries at or near term. Virchows Arch. 2016;468(4):503-7. https://doi.org/10.1007/s00428-015-1899-0.

9. Higgins RD, Saade G, Polin RA, Grobman WA, Buhimschi IA, Watterberg K, et al. Evaluation and management of women and newborns with a maternal diagnosis of chorioamnionitis: summary of a workshop. Obstet Gynecol. 2016; 127(3):426-36. https://doi.org/10.1097/AOG.0000000000001246.

10. Kyozuka H, Yasuda S, Hiraiwa T, Ishibashi M, Kato K, Fujimori K. Histological chorioamnionitis as a risk factor for preterm birth without disturbing fetal heart rate: a case-control study. Tohoku J Exp Med. 2017;243(4):289-95. https://doi.org/10.1620/tjem.243.289.

11. American College of Obstetrics and Gynecology Committee on Practice Bulletins-Obstetrics. ACOG practice bulletin number 49, December 2003: dystocia and augmentation of labor. Obstet Gynecol. 2003;102:1445-54.

12. Gifford DS, Morton SC, Fiske M, Keesey J, Keeler E, Kahn KL. Lack of progress in labor as a reason for cesarean. Obstet Gynecol. 2000;95:589-95.

13. Kjaergaard H, Olsen J, Ottesen B, Dykes AK. Incidence and outcomes of dystocia in the active phase of labor in term nulliparous women with spontaneous labor onset. Acta Obstet Gynecol Scand. 2009;88(4):402-7. https://doi.org/10.1080/00016340902811001.

14. Selin L, Wallin G, Berg M. Dystocia in labour - risk factors, management and outcome: a retrospective observational study in a Swedish setting. Acta Obstet Gynecol Scand. 2008;87(2):216-21. https://doi.org/10.1080/0001634 0701837744

15. Lencki SG, Maciulla MB, Eglinton GS. Maternal and umbilical cord serum interleukin levels in preterm labor with clinical chorioamnionitis. Am J Obstet Gynecol. 1994;170(5):1345-51. https://doi.org/10.1016/S0002-9378(13)90462-2.

16. Parer JT, Ikeda T, King TL. The 2008 National Institute of Child Health and Human Development report on fetal heart rate monitoring. Obstet Gynecol. 2009:114(1):136-8. https://doi.org/10.1097/AOG.0b013e3181ab475f.

17. Khong TY, Mooney EE, Ariel I, Balmus NC, Boyd TK, Brundler MA, et al. Sampling and definitions of placental lesions: Amsterdam placental workshop group consensus statement. Arch Pathol Lab Med. 2016 Jul; 140(7):698-713. https://doi.org/10.5858/arpa.2015-0225-CC.

18. Mi Lee S, Romero R, Lee KA, Yang HJ, Oh KJ, Park C-W, et al. The frequency and risk factors of funisitis and histologic chorioamnionitis in pregnant women at term who delivered after the spontaneous onset of labor. J Matern Fetal Neonat Med. 2011;24(1):37-42. https://doi.org/10.3109/14 767058.2010 .482622

19. Seong HS, Lee SE, Kang JH, Romero R, Yoon BH. The frequency of microbial invasion of the amniotic cavity and histologic chorioamnionitis in women at term with intact membranes in the presence or absence of labor. Am Obstet Gynecol. 2008;199:375 e1-5.

20. Kyozuka H, Yasuda S, Hiraiwa T, Nomura Y, Fujimori K. The change of fetal heart rate short-term variability during the course of histological chorioamnionitis in fetal sheep. Eur J Obstet Gynecol Reprod Biol. 2018;228: 32-7. https://doi.org/10.1016/j.ejogrb.2018.06.015.

21. Zervomanolakis I, Ott HW, Hadziomerovic D, Mattle V, Seeber BE, Virgolini I, et al. Physiology of upward transport in the human female genital tract Ann N Y Acad Sci 2007;1101:1-20, 1, 1, DOI: https://doi.org/10.1196/anna Is.1389.032.

22. Kim SM, Romero R, Lee J, Lee SM, Park C-W, Park JS, et al. The frequency and clinical significance of intra-amniotic inflammation in women with preterm uterine contractility but without cervical change: do the diagnostic criteria for preterm labor need to be changed? J Matern Fetal Neonatal Med. 2012:25(8):1212-21. https://doi.org/10.3109/14767058.2011.629256.

23. Romero R, Gomez-Lopez N, Winters AD, Jung E, Shaman M, Bieda J, et al. Evidence that intra-amniotic infections are often the result of an ascending invasion - a molecular microbiological study. J Perinat Med. 2019;47(9):91531. https://doi.org/10.1515/.jpm-2019-0297.

24. Kyozuka H, Fujimori K, Hosoya M, Yasumura S, Yokoyama T, Sato A, et al. The effect of maternal age at the first childbirth on gestational age and birth weight: the Japan environment and Children's study (JECS). J Epidemiol. 2019:29(5):187-91. https://doi.org/10.2188/jea.JE20170283.

25. Treacy A, Robson M, O'Herlihy C. Dystocia increases with advancing maternal age. Am J Obstet Gynecol. 2006;195(3):760-3. https://doi.org/10.1 016/j.ajog.2006.05.052 
26. Hautakangas T, Palomäki O, Eidstø K, Huhtala H, Uotila J. Impact of obesity and other risk factors on labor dystocia in term primiparous women: a case control study. BMC Preg Childbirth. 2018;18(1):304. https://doi.org/10.1186/ s12884-018-1938-3.

27. Blankenship SA, Raghuraman N, Delhi A, Woolfolk CL, Wang Y, Macones GA, et al. Association of abnormal first stage of labor duration and maternal and neonatal morbidity. Am J Obstet Gynecol. 2020;223:445 e1-15.

28. Gotsch F, Romero R, Kusanovic JP, Mazaki-Tovi S, Pineles BL, Erez O, et al. The fetal inflammatory response syndrome. Clin Obstet Gynaecol. 2007; 50(3):652-83. https://doi.org/10.1097/GRF.0b013e31811ebef6.

29. Kyozuka H, Fujimori K, Hosoya M. The Japan environment and Children's study (JECS) in Fukushima prefecture: pregnancy outcome after the great East Japan earthquake. Tohoku J Exp Med. 2018;246(1):27-33. https://doi. org/10.1620/tjem.246.27.

30. Yoneda S, Shiozaki A, Ito M, Yoneda N, Inada K, Yonezawa R, et al. Accurate prediction of the stage of histological chorioamnionitis before delivery by amniotic fluid IL-8 level. Am J Reprod Immunol. 2015;73(6):568-76. https:/ doi.org/10.1111/aji.12360.

\section{Publisher's Note}

Springer Nature remains neutral with regard to jurisdictional claims in published maps and institutional affiliations.

Ready to submit your research? Choose BMC and benefit from:

- fast, convenient online submission

- thorough peer review by experienced researchers in your field

- rapid publication on acceptance

- support for research data, including large and complex data types

- gold Open Access which fosters wider collaboration and increased citations

- maximum visibility for your research: over $100 \mathrm{M}$ website views per year

At BMC, research is always in progress.

Learn more biomedcentral.com/submissions 